\title{
MODELLING AND FABRICATION OF MICROCONTROLLER BASED SPEED CONTROL SYSTEM IN HYDRO TURBINE
}

\author{
E. KAVITHA ${ }^{1}$, ISMAIL KAKARAVADA ${ }^{2} \&$ Dr. M. R. S. SATYANARAYANA ${ }^{3}$ \\ ${ }^{1,2}$ Department of Mechanical Engineering, Prasad V Potluri Siddhartha Engineering College, Vijayawada, India \\ ${ }^{3}$ Department of Mechanical Engineering, GITAM, Visakhapatnam, India
}

\begin{abstract}
This article presents the modeling and fabrication of a novel microcontroller based speed control device for the turbine which is completely operated by PLC which can be used in the place of conventional governor. The turbine speed is a significant parameter during the production of electricity. To control the speed of the turbine, the flow input fluid of the turbine is controlled through a nozzle which has spherical. On the other hand, stability and range are major setbacks for the efficiency of the turbine. These are major limitations to limit the usage of conventional governors. To overcome this, the advancements in technology that is microcontrollers which are loaded with the Arduino program system have developed to control the speed and range of turbine for stable outputs. In the current work, various output were considered like a valve opening time, discharge, and response time. From the results, it is observed that the increase in the speed of the turbine leads to a hike in a valve opening time and discharge as well response time is decreased.

KEYWORDS:Microcontroller, Governor, Turbine, Nozzle \& Stability
\end{abstract}

Received: May 25, 2020; Accepted: Jun 15, 2020; Published: Jun 29, 2020; Paper Id.: IJMPERDJUN2020129

\section{INTRODUCTION}

The electrical power production is carried out in power plants through electro-mechanical generators which are driven by various power source like internal and external combustion engines, fission of radioactive fuel and kinetic energy of flowing water and wind. Generally, speed of steam turbine $3000-3600 \mathrm{rpm}$ with a rated frequency of 50 $\mathrm{Hz}$. The speed of the turbine varies by the reason of the load on the electric generator.The generator shaft is coupled with turbine shaft. So, the constant speed is not obtained during the operation. The speeds of steam turbine are controlled by mechanical governor to maintain stability, response time and isochronisms. Even though, there few limitations like frequency fluctuation in power system. Controlling the input of the turbine to maintain the speed constant is most significant factor in a power plant. Frequency variation also decreases the life of the equipment as directly have an effect on the overall production of the plant. The instability of frequency in power system causes to harmful effectswhich needs to protect from it. For this a novelmicrocontroller based under/over frequency relayswitches was designed to protect the circuit.. In the current articlethe usage of microcontroller AT89S52 used for protecting system to avoid the problem of frequency variations. During the operational conditions the oscillation infrequency deviated from rated value prone to trip of electromagnetic relay and isolatesthe power system from its harmful effect. An electromechanical protective relay operatesthrough magnetic attraction, or magnetic induction. A prototype mini hydro power plant was designed with a capacity of $750 \mathrm{~W}$ with a cross flow model turbinewhich is attached $500 \mathrm{~W}$ capacity generators. In this prototype operations are controlled and realized by using a PIC16F877 microcontroller. The generated frequency and voltage are measured with the zero crossing circuit with transfer's microcontroller. The working principle of micro controller purely depends on the frequency error. As the error 
occurs in system which generates PWM signals. The PWM signals are input for the $\mathrm{H}$ bridge circuit and connected with setting wing of DC motor.The rotary motion of the motor was shifted to the setting wing via a threaded shaft and a mechanical arm. The setting of the number of turns on the turbine,This mechanism sets the value of the frequency used to generates $500 \mathrm{~W}$ with the turbine could be kept on desired levels. After the design, Loading and load shedding performances of the designed system were reported.

The speed regulator of a general diesel engine is known's as a governor. In order to manage engine speed, the governor directs the quantity of oil using fuel bracket. The fuel rack is associated to throttle actuator lever which is driven from microcontroller. The actuator motion is restricted to accomplishdesignated rpm so necessary pulse width modulation duty cycle to drive actuator is premeditated from digital PID algorithm. PIC 16F877A microcontroller support hardware is developed for the execution of the controller. The structuremostlyengages with interfacing hardware and the software for PID algorithm. Aundisrupted PID controller is directed by an equation which explains the vibrant time changeable behaviour of the input or the error signal. This is digitized using arithmetical approximations and is automated in the microcontroller. This system is a closed loop control system with feedback signal engenderd by a digital magnetic pickup, which gives a pulse output which is TTL friendly. The PID algorithms along with the hardware achieve the speed control of the diesel engine. The hardware and software are validating in real time by allowing for different speed situations. The speed control of the turbine has been studied for improvement stability by several researchers [1-12].Meenakshi et al. [1], projected a simple method for execute the speed control of DC motor by means of digital PID algorithm. Intel 8085 microprocessor based hardware is developed for the accomplishment of the controller. The system generally involves interfacing hardware and the software for PID algorithm. A continuous PID controller is directed by an equation which portrays the dynamic time unstableactions of the input or the error signal. A digital to analog converter interfaces the power control to the microcomputer. The PID algorithm along with the hardware achieves the speed control of the DC motor. The hardware and software are authenticates in real time by considering different speed settings. Qian Xiong et al. [5], investigated ondistinct factors to control engine speed and develop algorithm to control speed by managing the charge and spark advance angle collectively. This algorithm makes it possible to to run the engine at stable condition. The experiments were conducted by using of electronic control throttle with new algorithm provides excellent idle speed control.

Y. Gu et al. [6], projected a novel approach to digital governing system for a gas engine based on TMS320F28335 micro controller. In this speed governor system a hall sensor A04E is used to determine speed.L298N microcontroller is used to drive the step motor; torque vector control is used to sub devise the angular of step motor. The multi phase control system that is fuzzy control and PID control are used together in which fuzzy control implement fast control, PID control implement accurate control. This new control systems improves dynamic response while the load change, and keep the governor performing well in a wide operating range.

\section{PROBLEM STATEMENT}

The present research work deals with the modeling and fabrication of a novel microcontroller based speed control device for the turbine which is completely operated by PLC which can be used in the place of conventional governor. The analysis includes Prediction of turbine speed which is a significant parameter during the production of electricity. Prediction of stability and range are major setbacks for the efficiency of the turbine. To develop the Arduino program for the microcontroller for proper ease. 


\section{METHODOLOGY}

The general model is developed for the fabrication of a novel microcontroller based speed control device for the turbine which is completely operated by PLC which can be used in the place of conventional governor. The present work is modeled in CATIA, later Arduino Program is developed for the microprocessor and various output were considered like a valve opening time, discharge, and response time.

For the present problem, modeling and fabrication of a novel microcontroller based speed control device for the turbine which is completely operated by PLC is used in the place of conventional governor which is as shown in Figure 3.1 .

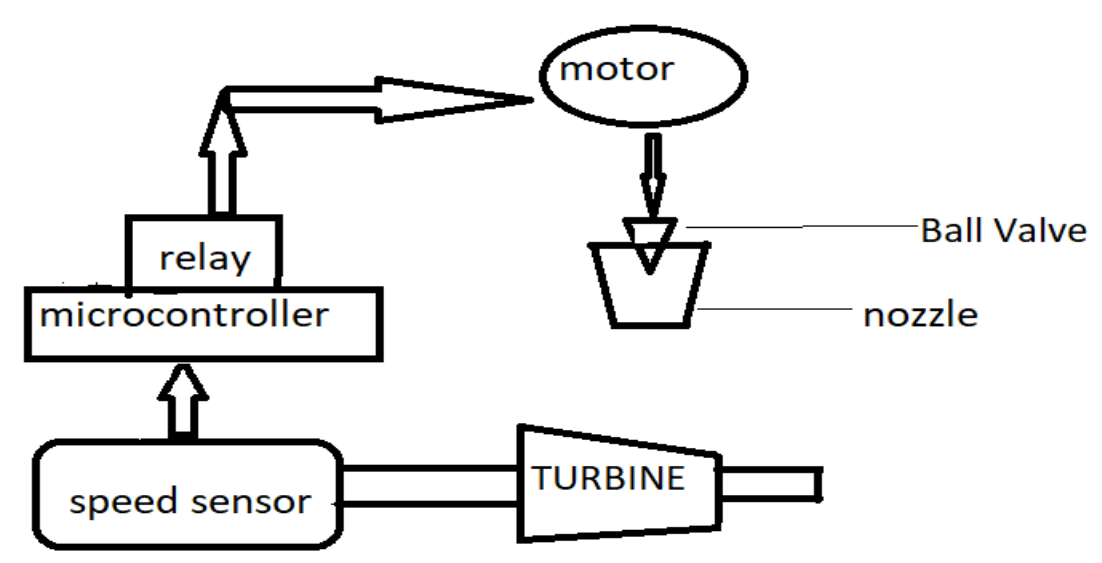

Figure 1: ModellingOf Microcontroller Based Speed Control Device.

This type of model is adopted in order to accommodate the turbine speed which is a significant parameter during the production of electricity. In order to control the speed of the turbine, the flow input fluid of the turbine is controlled through a nozzle which is spherical. On the other hand, stability and range are major setbacks for the efficiency of the turbine. The above mentioned parameters are major limitations to limit the use of conventional governors. To overcome this, the microcontroller is loaded with the Arduino program into the system that has been developed to control the speed and range of turbine for stable outputs. In the present work, various outputs were considered like a valve opening time, discharge, and response time.

\section{Experimentation Setup}

The complete diagram of the Replacement of governor with an microcontroller in power plant is given below. The turbine which is rotating at high speed in power plant due to high velocity of the input fluid from the nozzle is stricking the blades of the turbine. 


\section{2-D view of the Project}

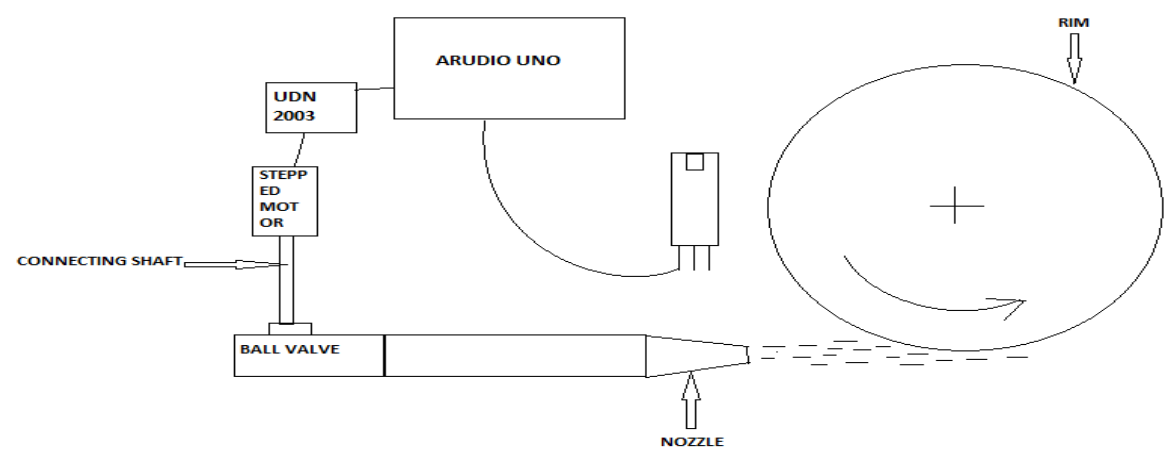

Figure 2:2D View of the Model.

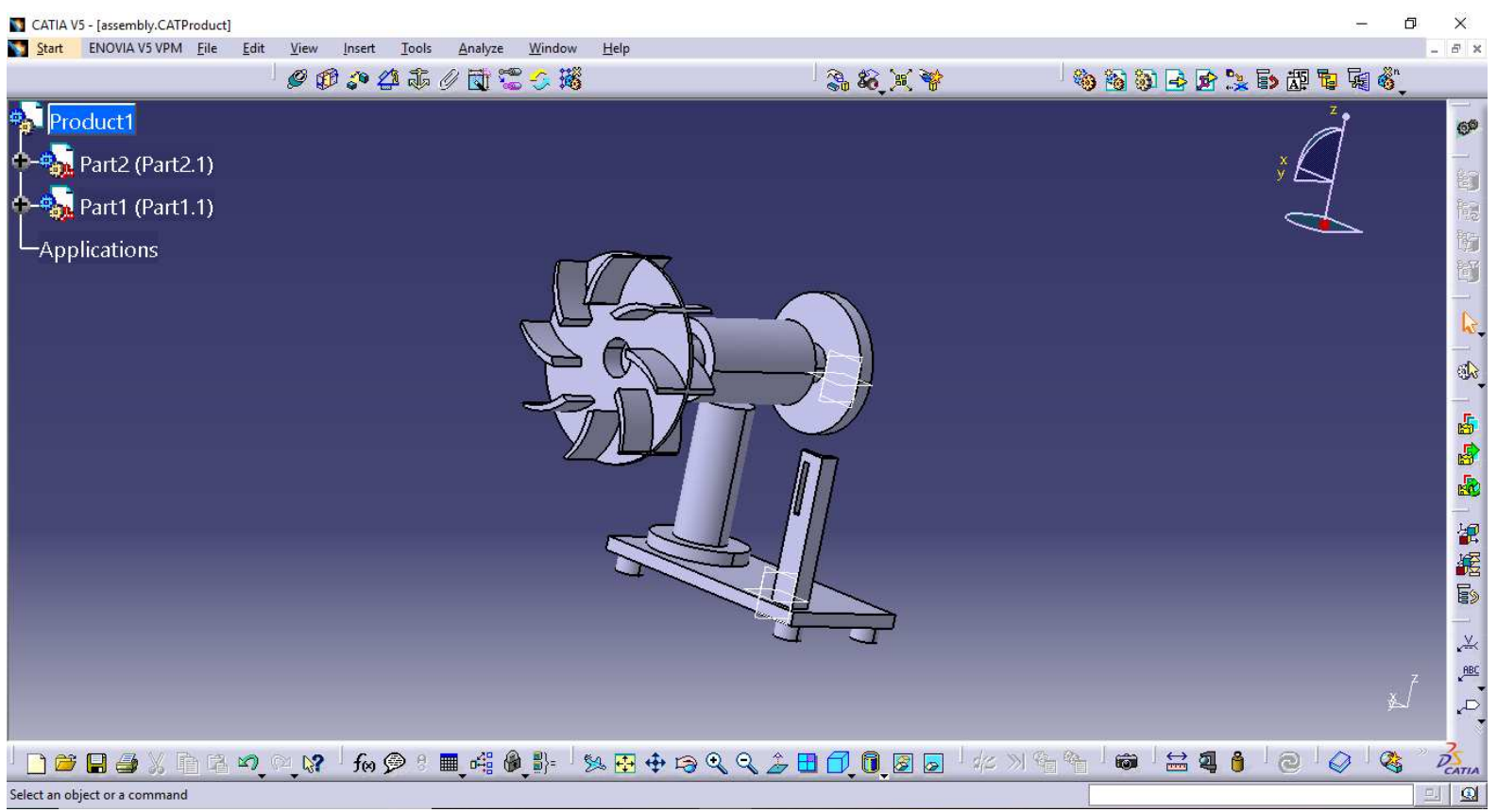

Figure 3: 3D View of the Model.

The turbine rotates at aconstant speed in order to have a frequency ofpower at $50 \mathrm{~Hz}$ or $60 \mathrm{~Hz}$. Due to the different load conditions the speed of theturbine will decrease. The speed sensor senses the speed of the turbine and sends to the arudino microcontroller. So, the speed sensor i.e.., IR speed sensor is connected to microcontroller. Then the Microcontroller is connected to the servo motor. The microcontroller is programmed to some preset speed using the Arduino software. The servo motor is connected to the ball valve which will vary the input fluid.

For example, the turbine speed is programmed to $1500 \mathrm{rpm}$. If in case the speed is above the preset speed value then the signal is sent to the microcontroller from the speed sensor. The microcontroller will send signal to the servo motor. This motor will sweep to some angle and then the ball valve will also close to some angle, the input fluid will be reduced and therefore the speed is also reduced and the speed will reach the present value. If in case the speed is less than the present value, then the servo motor will sweep in opposite direction. The above mentioned process will be repeating. Finally the stability will be achieved very quickly where the response time is less. 


\section{MICROCONTROLLER (ARDUINO UNO)}

A computer can run thousands of programs, but microcontrollers are special purpose computers which can perform one program efficiently. An integrated circuit contains a microprocessor along with memory and associated circuits that controls some or all of the functions of an electronic device or system. Microcontrollers are embedded inside some other devices so that they can control the features or actions of the product which are also referred to as "embedded controller". The microcontroller is often low power device. A computer many consume 50 watts. But in a microcontroller a battery operated 50millwatts is enough. The microcontroller which we use in our workis Arduino Uno.

\section{PIN DIAGRAM OF MICROCONTOLLER (Arduinouno)}

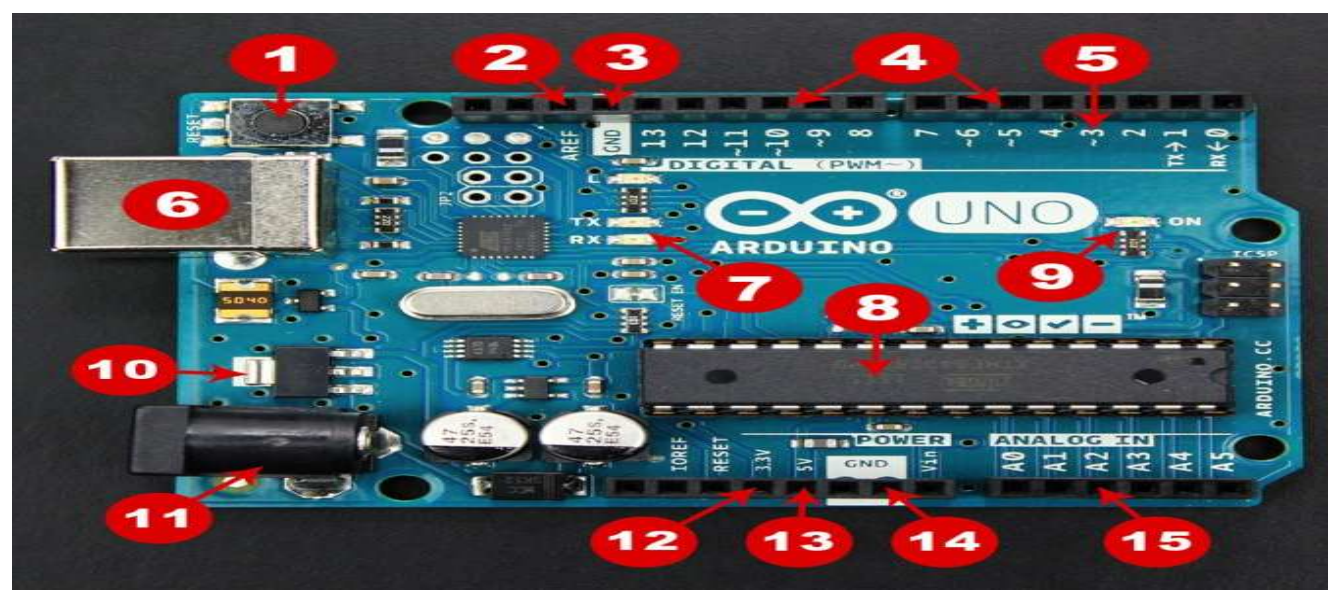

Figure 4: Pin Diagram of Arduino.

\section{PROGRAMMING SOFTWARE (ARDUINO.CC)}

Programming software for Arduino Uno microcontroller is Arduino.cc. This software is very easy to write the program, compile the program and to upload the program. The Arduino.cc is user interface software. The every arduino program (sketch) has two parts:

Void setup () - sets thing up that have to done once and then don't happen again.

Void loop () - contains the instructiond that get repeated over and over until the board is turned off. 

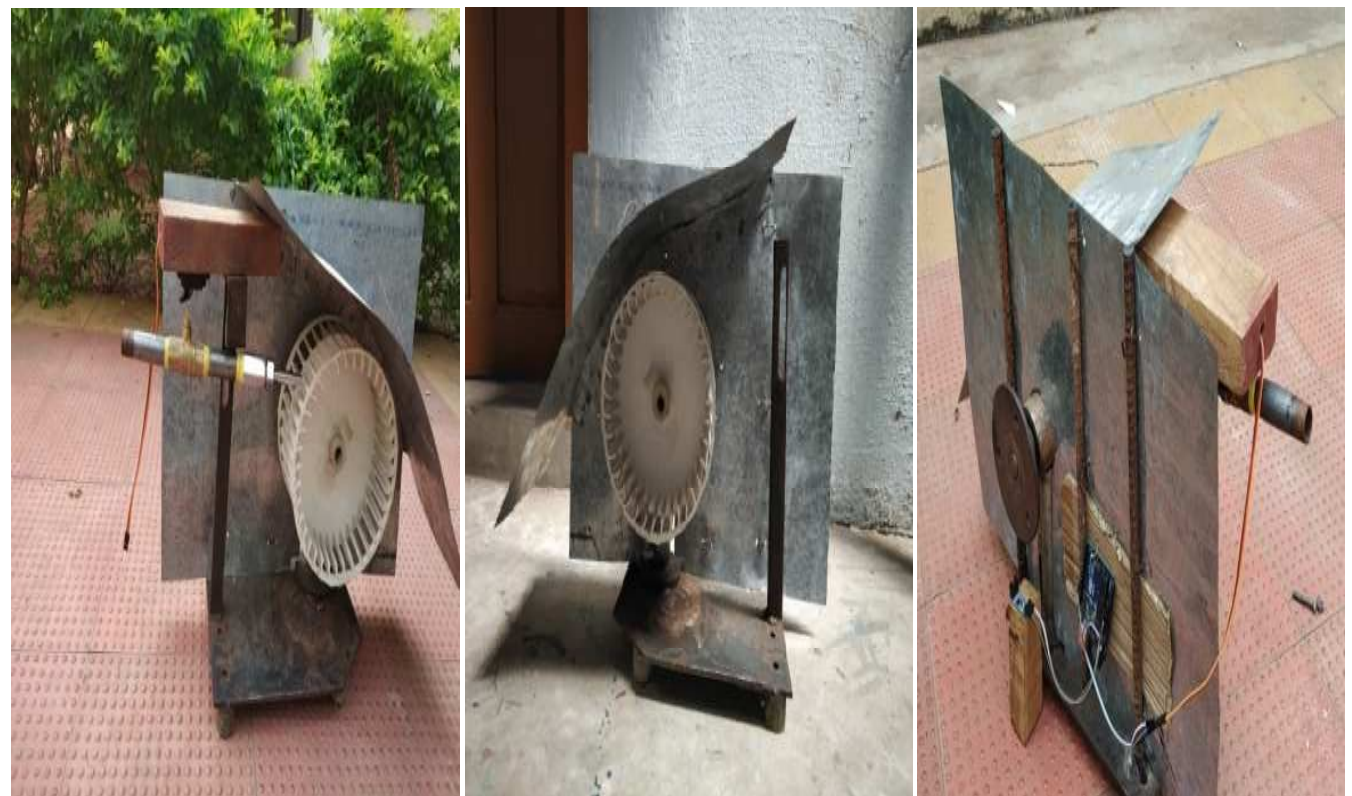

Figure 5: Fabrication of Microcontroller based Speed Control Device for the Hydro Turbine. RESULTS AND DISCUSSIONS

Variation of Speed w.r.t Valve Opening

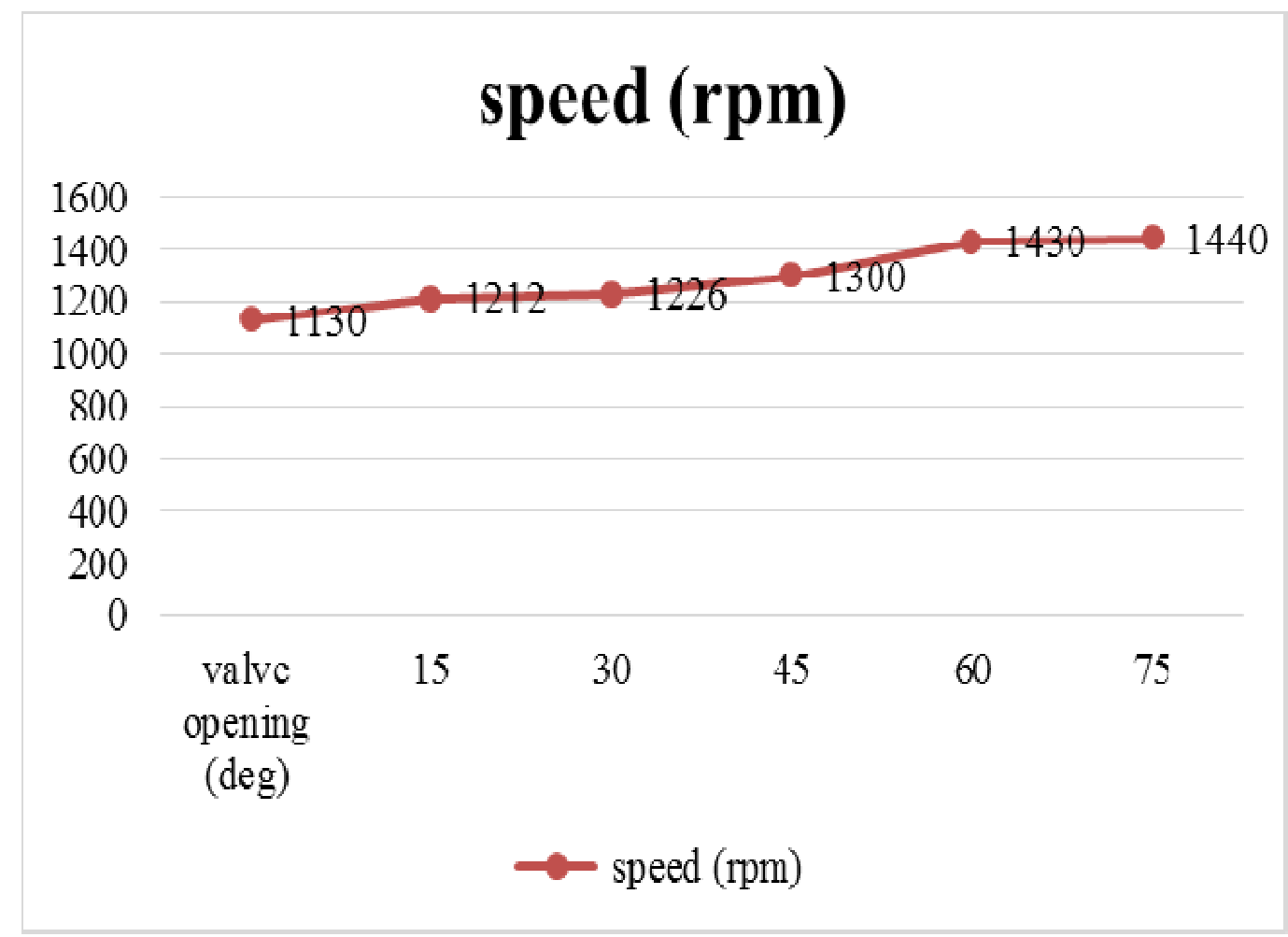

Figure 6: Variation of Speed w.r.t Valve Opening.

The variation of speed with respect to valve opening is shown in the Figure 4.1. The valve opening are represented on $\mathrm{x}$ - axis and speed on $\mathrm{Y}$-axis. It is also observed that when the valve opening is at zero(deg) the speed is raising to a certain value and on further increasing of the valve the speed is constantly increasing. It is evident from the figure that as the valve opening increases there is slight increase in speed.This is due to the reason that if flow rate is increased then power input will also be increased. 


\section{Variation of Discharge w.r.t Valve Opening}

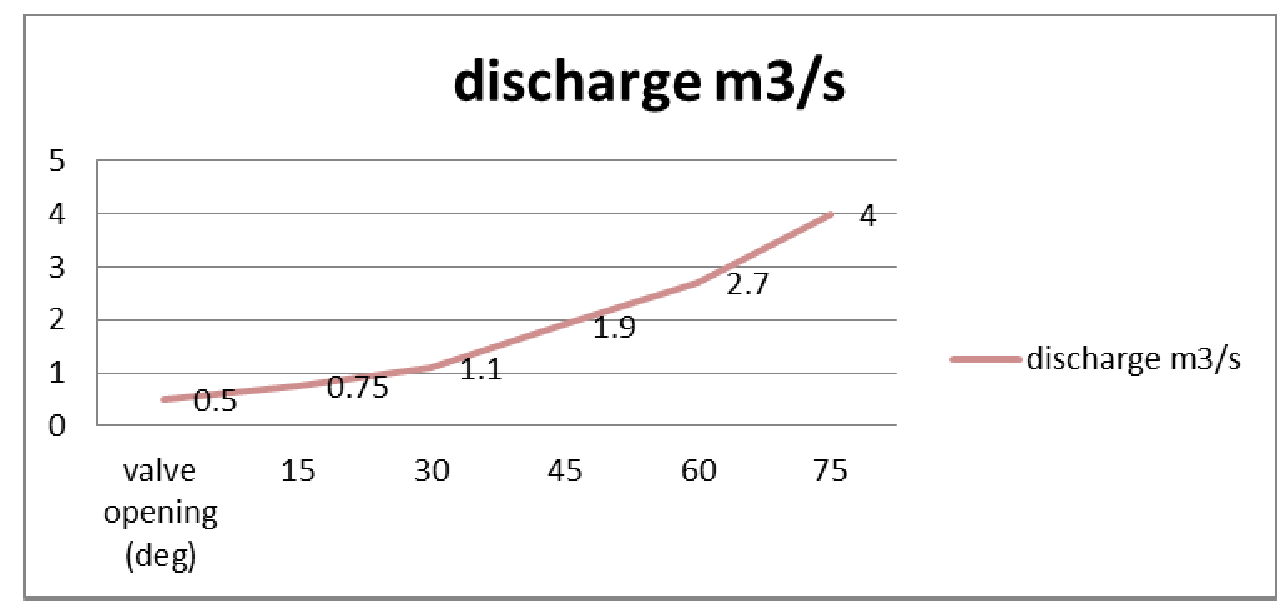

Figure7: Variation of Discharge w.r.t Valve Opening.

The variation of discharge with respect to valve opening is shown in the Fig.4.2. The valve opening are represented on $\mathrm{x}$ - axis and discharge on $\mathrm{Y}$-axis. It is also observed that when the valve opening is at zero(deg) the dischareg is raising to a certain value and on further increasing of the valve the discharge is increasing. It is evident from the figure that as the valve opening increases there is an increase in the discharge.

\section{Variation of Speed w.r.t Response Time}

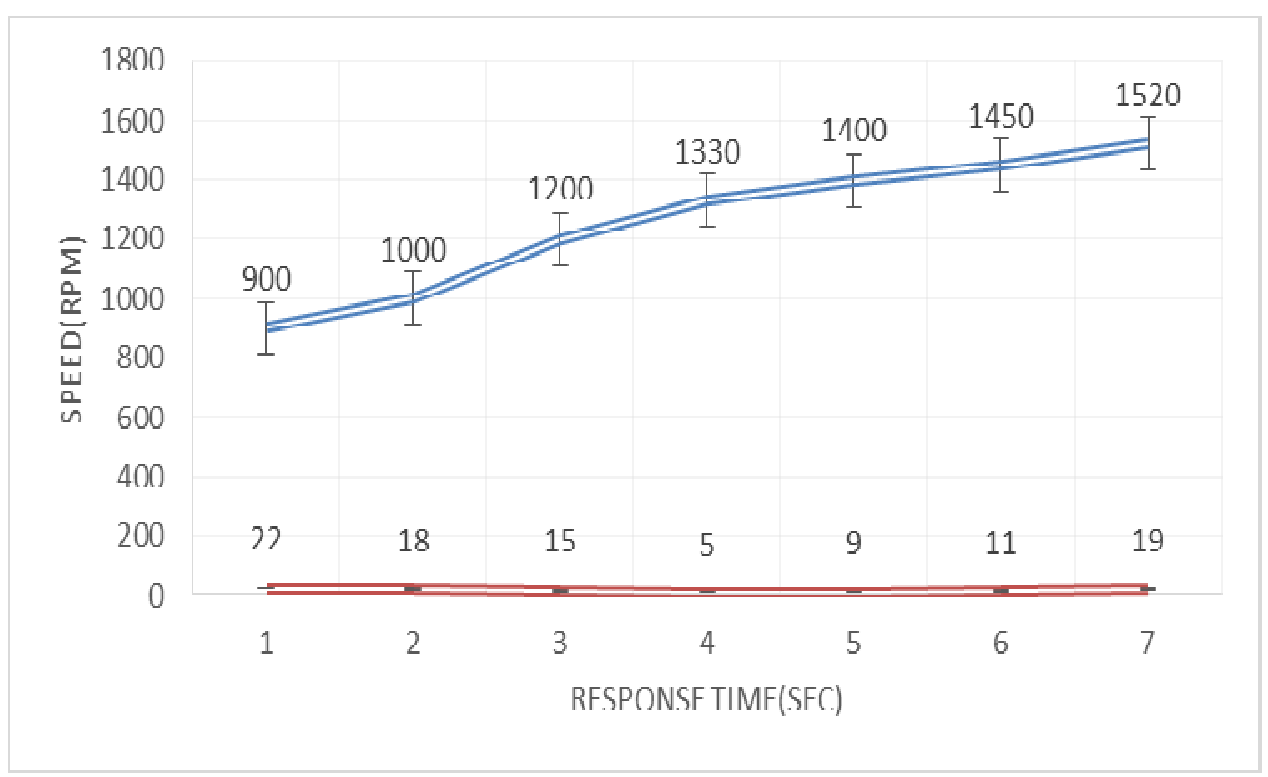

Fig 8: Variation of Speed w.r.t Response Time.

The variation of speed with respect to response time is shown in the Fig.4.3. The response time is represented on $\mathrm{X}$ - axis and speed on $\mathrm{Y}$-axis. It is observed that the rate of response is quick. X-axis represents the response time in sec(i.e., how quick the microcontroller maintains reference or preset speed). Y-axis represents the current speed of turbine. It is also observed that how quick the above figure achieves the reference or preset speed. For example, $22 \mathrm{sec}$ time is required to achieve reference or preset speed from 900rpm. 


\section{CONCLUSIONS}

The replacement of governor with microcontroller in power plant is working with satisfactory a condition which helps to know how to achieve the constant speed of a turbine. It is able to understand the difficulties in maintaining the tolerances and also quality. The application of this system is high when compared to the cost. By using more techniques, they can be modified and developed according to the application. This research work is an experimental effort to demonstrate how to maintain the constant speed by using a microcontroller.

\section{ACKNOWLEDGEMENTS}

The authors thank the management ofPrasad V Potluri Siddhartha Engineering College,Vijayawada, India for extending their support to conduct the study.

\section{REFERENCES}

1. Dr. M. Meenakshi, Microprocessor Based Digital PID Controller for Speed Control of D.C.Motor, IEEE First International Conference on Emerging Trends in Engineering and Technology, pp.960965,IEEE(2008).

2. Tianjiao, Governor Based on Step Motor and PLC, Tianjin Flying Electric Co Ltd, Hydroelectric Services Equip Co Ltd.

3. David J. McGowan \& D. John Morrow, Multiple Input Governor Control for a Diesel, Dual fuel technologies generating set, IEEE transactions on energy conversion, vol. 23, NO. 3, pp.851859,IEEE(2008).

4. QianXiong, Jinliang Shi, Guorong Chen, Zeng Peng, "Research on Idle Speed Control for EFI Gasoline engine with ETB", pp. 222-226(2009)

5. Y.Gu \&H.Y.Yu, “Digital Speed Governor System Based on TMS320F28335 Chip for a Gas Engine”, 2010 International Conference on Communications and Intelligence Information Security, pp.40-43, IEEE (2010)

6. Goyal, Lalit, OM PRAKASH Mahela, and S. U. N. I. L. Goyal. "A survey of self-excited induction generator research." Int. Journal of Electrical and Electronics Engineering 2.1 (2013): 31-40.

7. Hans-Martin Streib and Hubert Bischof, "Electronic throttle control (ETC): a cost effective system for improved emissions, fuel economy, and drivability”, SAE Technical Paper Series. Warren dale, PA, 960338, pp. 165-172(1996).

8. Jiang Fangyi, GaoShilun, Zhang Jie and Huang Wei, "Development of Electronic Governor for Diesel Engine Based on Embedded RTOS”, pp.218-221, IEEE,(2006).

9. Sung hoon Koo, Hyeong soon moon, "Development of electronic governor and simulator for the generating diesel engine”, ICROS-SICE International Joint Conference Japan, pp.29002902,IEEE (2009).

10. Das, S., Debabhuti, N., Das, R., Dutta, S. \& Ghosh, A. “Embedded system for home automation using SMS.” Proceedings of theIEEE International Conference on Automation, Control, Energy and Systems (ACES), pp. 1-6, (2014).

11. Bhaskar, B., \&Swarnalatha, R. "Smart home automation system using AVR microcontroller"International Journal of Advanced Technology in Engineering and Science, 3(2), 234-342,(2015).

12. Jawarkar, N. P., Ahmed, V., Ladhake, S. A., \&Thakare, R. D. Micro-controller based remote monitoring using mobile through spoken commands. Journal of Networks, 3(2), 58-63.

13. Thomas, L., James, S.A., Joseph, S., Arya, K.B., Narah, T. \&Pangu, O. “Automatic Speed Control of Vehicles using RFID”, International Journal of Engineering and Innovative Technology, 3, 118-120. (2014). 